\title{
Importance of development of STEM education for petrology and mineralogy
}

\author{
Tomohiro Takebayashi $^{1}{ }^{*}$, Yoshisuke Kumano ${ }^{1}$ \\ ${ }^{1}$ Information Science and Technology, Graduate School of Science and Technology, Shizuoka \\ University, Japan \\ * Corresponding Author: taketomo.geology@gmail.com \\ Received: 19 October 2015; Revised: 11 April 2018; Accepted: 3 May 2018
}

\begin{abstract}
Rocks and minerals are very important materials for studying Earth Sciences. They are used to investigate the planetary history and evolution and are utilized as resources to support our lives. At present, it is critical for all countries to secure a stable supply of mineral resources, and it is necessary to understand the deposits and the growing mechanisms of minerals. In Japan, elementary and junior high school students study igneous and sedimentary rocks and some other kinds of minerals. In this research, we conducted a questionnaire for 154 Japanese junior high school students to investigate their (1) knowledge of minerals, and (2) petrology and mineralogy with respect to usefulness of rocks and minerals to our living. First, about $95 \%$ of the students could answer the names of the stone, including those who mainly answered jewel names. However, $~ 56 \%$ students could not answer the benefits of minerals.In high school, 36\% students learned Basic Earth Sciences and $1.2 \%$ learned Earth Sciences (MEXT, 2017). There is concern that most of the Japanese people have few opportunities to learn Earth Sciences. As NGSS showed in 2013, Earth and Space Science are major fields of STEM learning. Conclusively, it is necessary to stop memorizing subjects and instead modify the Earth Sciences with respect to STEM education. In this paper, we discuss the student's attitudes towards petrology and mineralogy so as to propose the Earth STEM education.
\end{abstract}

Keywords: rock, mineral, STEM, earth science, NGSS

How to Cite: Takebayashi, T., \& Kumano, Y. (2018). Importance of development of STEM education for petrology and mineralogy. Jurnal Inovasi Pendidikan IPA, 4(1), 98-103. doi:http://dx.doi.org/10.21831/jipi.v4i1.18525

http://dx.doi.org/10.21831/jipi.v4i1.18525

\section{INTRODUCTION}

In Earth science, which is an important aspect of our lives, petrology and mineralogy are considered essential learning fields for understanding material evidence. This is because rocks and minerals are used to elucidate the history and evolution of the planet. Till now, 5256 mineral species of the earth have been discovered, and many new minerals are still being discovered (International Mineralogical Association, 2017). Among these diverse minerals, certain minerals serve as resources. For instance, rare metals such as gold, copper, and rare earth elements are necessary metal minerals. In the modern society, with the spread of high-tech equipment, the demand for resources has also increased rapidly. In order to obtain a stable supply of resources, it is necessary to understand the glowing mechanism of minerals and the origins of ores. For instance, there are studies on the conditions under which rare metals such as gold and silver can be produced (Huston, 2000; Simon, Kesler, \& Chryssoulis, 1999; Yakushi \& Enjoji, 2004). In recent years, the rare earth of the seafloor has attracted much attention in Japan (Kato et al., 2011). Given that rocks and minerals substantially contribute to our lives, we need to convey the importance of petrology and mineralogy. In the 21st century, petrology and mineralogy should include not only scientific fields but also fields such as technology and engineering. This paper aims to determine whether children understand the importance of rocks and minerals in our lives. 
Jurnal Inovasi Pendidikan IPA, 4 (1), 2018 - 99

Tomohiro Takebayashi, Yoshisuke Kumano

Table 1. Learning Contents of Rocks and Minerals in Elementary and Junior High Schools in Japan

\begin{tabular}{|c|c|c|c|c|}
\hline No. & Type & Name & Elementary School & Junior High Schoo \\
\hline 1. & sedimentaly rock & mud stone & + & + \\
\hline 2. & sedimentaly rock & sand stone & + & + \\
\hline 3. & sedimentaly rock & conglomerate & + & + \\
\hline 4. & sedimentaly rock & limestone & & + \\
\hline 5. & sedimentaly rock & chart & & + \\
\hline 6. & sedimentaly rock & tuff & & + \\
\hline 7. & igneous rock & ryorite & & + \\
\hline 8. & igneous rock & andesite & & + \\
\hline 9. & igneous rock & basalt & & + \\
\hline 10. & igneous rock & granite & & + \\
\hline 11. & igneous rock & diorite & & + \\
\hline 12. & igneous rock & gabbro & & + \\
\hline 13. & mineral & quartz & & + \\
\hline 14. & mineral & feldspar & & + \\
\hline 15. & mineral & biotite & & + \\
\hline 16. & mineral & amphibolite & & + \\
\hline 17. & mineral & olibine & & + \\
\hline 18. & mineral & pyroxene & & + \\
\hline 19. & mineral & magnetite & & + \\
\hline 20. & fossil & fossil & + & + \\
\hline
\end{tabular}

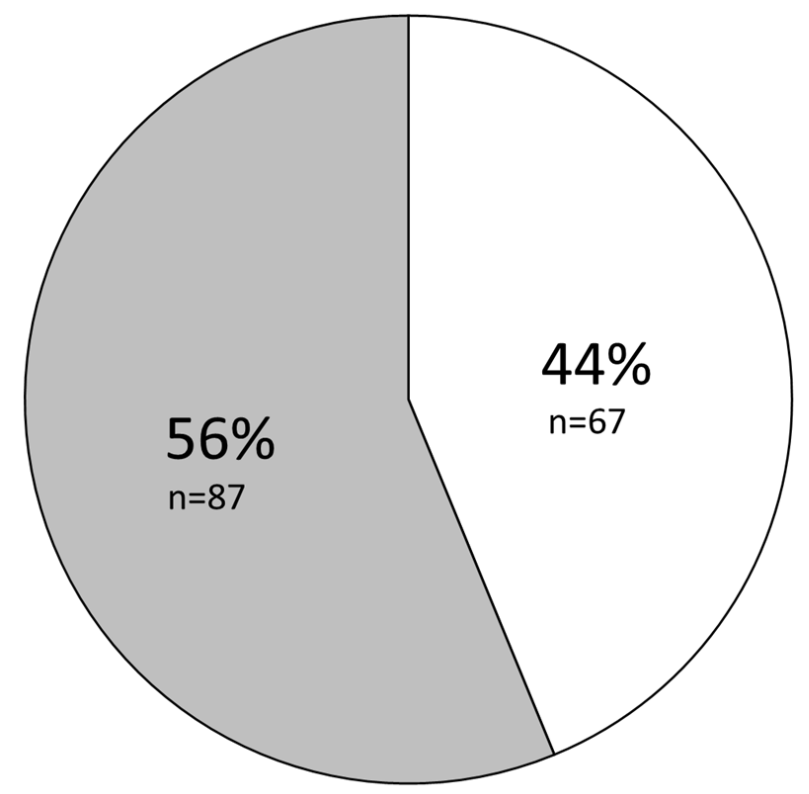

I think so. $\square$ I don't think so + Not sure

The $3^{\text {rd }}$ grade of Middle school students $(n=154)$ Boy: 83 / girl 71

Figure 1. Do you think that rocks and minerals are useful to our lives? 


\section{METHOD}

A questionnaire survey was conducted for 154 junior high school students (boys: 83, girls: 71; they are third grade) of the Shizuoka Junior High School attached to the Shizuoka University School of Education on July 20, 2017. The Shizuoka Junior High School has a higher deviation value than other junior high schools in the Shizuoka area.

Japanese children learn the names of several kinds of rocks and minerals at the elementary and junior high school levels (Table 1.). Thus, the respondents considered in our study had studied igneous rocks and sedimentary rocks in their first year of junior high school. Two questions were administered to the students. The first question was "Do you think that rocks and minerals are useful to our lives?" The answer format for this question was a selection formula and a free description for writing reasons. The choices for this answer were "yes," "no," and "not sure." The second question was "Please show the name of the mineral names that you know." For this question, the respondents were asked to answer using a free-described formula, and the number of mineral names was not limited.

\section{RESULT AND DISCUSSION}

\section{Result}

The results of the questionnaire survey are shown in Figure 1. Sixty-seven students (41.6\%; 47 boys, 20 girls) answered that rocks and minerals are useful to our lives, 39 students (24.2\%; 18 boys, 21 girls) answered that rocks and minerals are not useful to our lives, and 55 students $(34.6 \% ; 18$ boys and 37 girls) answered that they were not sure. Here, it should be noted that $58.4 \%$ of the respondents answered that "Rocks and minerals are not useful in our life" or "Not sure if rocks and minerals are useful in our life". This indicates that more than a majority of the students were not aware of the importance of rocks or minerals.

The respondents also cited the reasons for their answer choices for the first question. A total of 147 students out of 154 answered their reasons using sentences. From these sentences, words were extracted for each noun, verb, and adjective and then compared based on the three answer choices. The list of extracted words is shown in Figure 2.

For the second question, $146(95 \%)$ out of 154 students gave answers. Since there was no limit on the number of minerals, the students tried to answer the name of the minerals that they remember. The results are shown in Fig. 2.1. The most commonly mentioned minerals were biotite $(n=79)$, quartz $(n=61)$, pyroxene $(n=54)$, feldspars $(n=53)$, and diamonds $(n=50)$. Other answers included rock names and jewelry names in addition to the names of minerals. Among them, 37 students gave jewelry names in their responses, accounting for $20.3 \%$ of the total respondents, and 25 students answered rock names, accounted for $16.4 \%$ of the total respondents.

\section{Discussion}

The majority of students did not know the significance of learning rocks and minerals

Since the majority of students $(58.4 \%: \mathrm{n}=$ 84) answered "Rocks and minerals are not useful in our life" or "Not sure if rocks and minerals are useful in our life," it can be inferred that junior high school students do not understand the significance of learning rocks and minerals but simply treat them as items for memorization. The reasons given by the students who answered "Rocks and minerals are useful in our life" indicate that they are aware that rocks and minerals are utilized for resources, electronic equipment, building materials, or decorative materials. Here, the students probably understand them as a generation of profit or benefit by applying minerals, not utility value by usage of minerals themselves alone. On the other hand, according to the reasons cited by students who chose "Rocks and minerals are not useful or not sure if rocks and minerals are useful", the students did not use specific names but described more negative sentences. Furthermore, when we asked the students to tell us any mineral names in their knowledge, 95\% of the students answered the names of rock, mineral, and jewel. Thus, with the consideration of these tendencies, the students know the names of rock, mineral, and jewel, but they most likely memorize the names even without understanding their significance.

The student's future without knowing the significance of learning rocks and minerals

Rocks and minerals are indispensable as a natural resource in the modern society. For instance, all the electrical appliances utilize metal minerals. Energy resources used for a comfortable living are extracted from minerals. 
Various rocks are used for stone materials and decorative materials of a building. From these instances, the utilization of rocks and minerals in our life can be an important foundation for supporting the modern society. In the present Japanese science textbook, rocks and minerals are explained in terms of igneous rock and sedimentary rock during the first school year. The engineering usage of those minerals is introduced in the column section. According to the current teaching guidelines, the contents of rocks and minerals will not be learned from the second school year (Ministry of Education
Culture Sports Science and Technology, 2017). In addition, because the learning rate among the Japanese high schools is $36 \%$ for basic earth science and $1.2 \%$ for earth science, the students have quite few opportunities to learn earth science when they advance to high school. In other words, children have few opportunities to learn the basic knowledge connecting to technological development and resource development. Are these children satisfied by simply memorizing the minerals without knowing the significance of their existence?

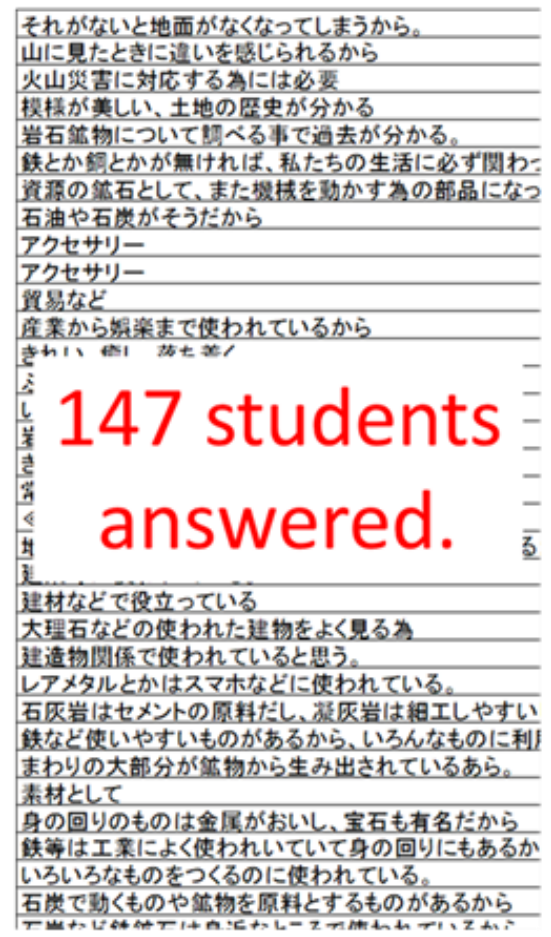

e.g.

- material

- coal

- Accessories

- it's beautiful

- smartphone

- Electronics

- Architecture

- marble

- building

- A relationship

- history

- land

- Tuff

- Limestone

- cement

- land

- it can

- Personal belongings

- to make

e.g

- Do not know

- opportunity

- Everyday

- A museum

I don't think so - place

+ I'm not sure - Geologist

- Not involved

- usually

- Awareness

- Concrete

- Existence

- meaning

- Mountain climbing

- To use

- touch

- Everyday

- study

- Personal use

- Volcanic zone

Figure 2. Word extraction from the answers of 147 students. 


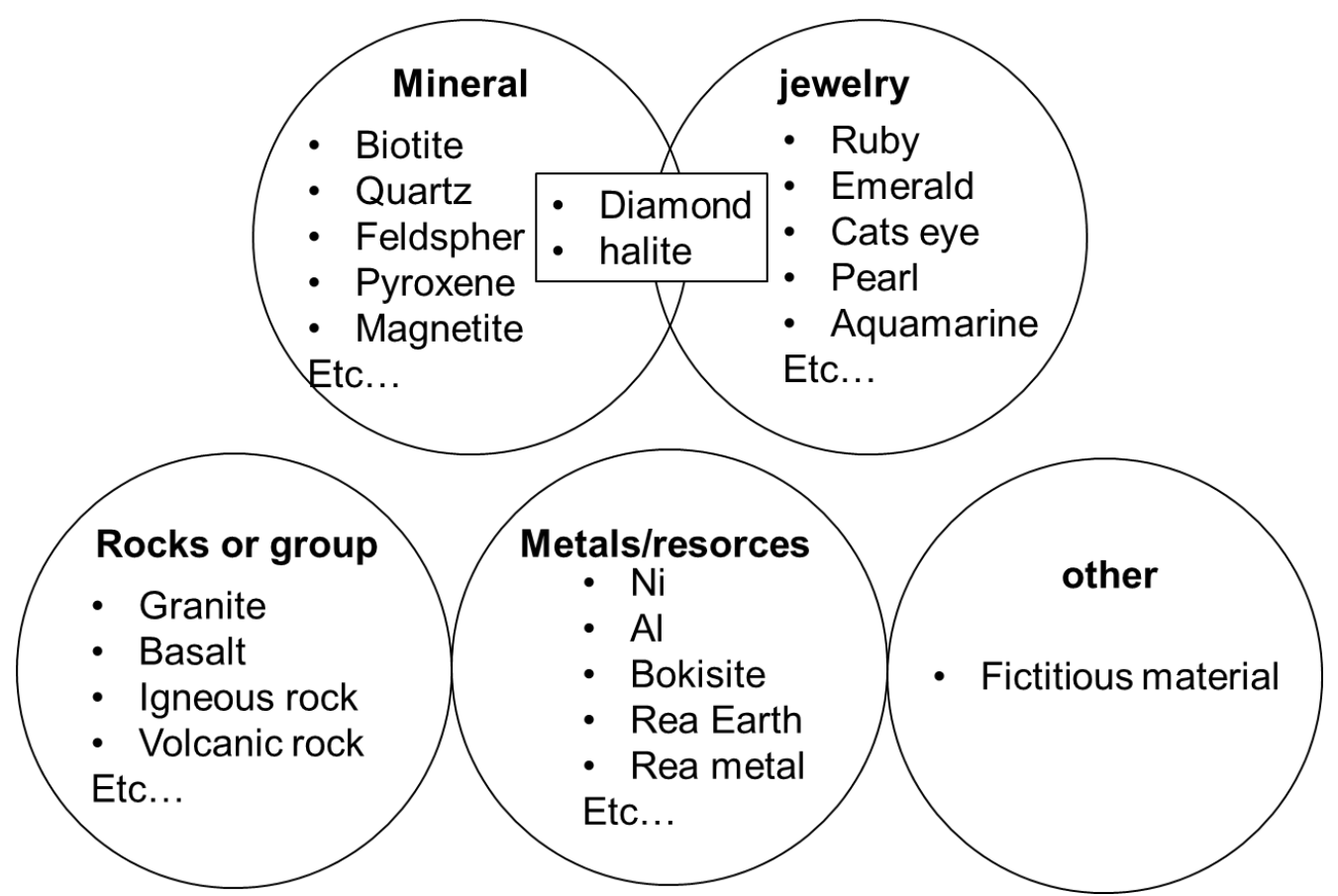

Figure 3. "Please write the name of the mineral you know." $95 \%$ of students $(n=146)$ answered. Answer type: 99 types

Development of teaching materials: Proposal of STEM (Science, Technology, Engineering, and Mathematics) in petrology and mineralogy

The proposal of development of teaching materials and education model will be discussed and adopted with reference to the STEM education in the US. Science education in the US is based on the STEM education, i.e., science, technology, engineering and mathematics, advocated by NGSS (Next Generation Science Standards). STEM education is also applied to NASA (National Aeronautics and Space Administration) and USGS (US Geological Survey) in the geoscience field, and the development of teaching materials is also progressing for each target age. Moreover, NASA and USGS develop their own teaching materials and conduct practical education using these teaching materials. For instance, in the case of NASA, scientists and engineers provide science education to the general public by preparing the curriculum. In recent years, SNS (Social Networking Service) has become popular, and the latest scientific data is provided to citizens through this service. Science education in the US develops cross-disciplinary teaching materials without segmentation of science fields like in Japan. Therefore, for a particular scientific issue, it conducts a problem-solving type of scientific education by utilizing not only science but also engineering, technology, and mathematics skills.

Currently, science education in elementary and junior high schools in Japan is divided into four fields of physics, chemistry, and biology, and STEM learning materials development and practice are advanced stages in these four fields. Studies have shown that it is possible to adapt STEM to Japanese science education (Kumano, 2016; Saito, Okumura, \& Kumano, 2017). Therefore, we propose the application of STEM education as a solution to problems such as simple memorization of rock and minerals. The STEM concept can also be applied to the field of petrology and mineralogy. The science field will be related to the genetic study of rocks and minerals and the quest for earth evolution. The field of technology and engineering is involved in the secondary use and industrial use of rock and minerals and the instrumental analysis for minerals. Then, the field of mathematics is involved with thermodynamic calculation and substance calculation. Therefore, when focusing on rocks and minerals as educational materials, it is highly expected that the development of STEM teaching materials will be successful with the use of these rocks and minerals. According to the science edition of commentary to the curriculum guidelines for junior high school students in Japan, there is a reference in terms of the development of science and technology. It 
describes that there is a necessity to incorporate engineering elements such as "Effectiveness of resources and energy resources" or "Deep-sea exploration" in science as a specific descriptions (MEXT, 2017). In other words, the science field and the engineering field are closely related to each other in the field of education, and it currently requires cross-field learning for both fields. For that reason, when considering future education through petrology and mineralogy, it is necessary to construct an educational model with the concept of STEM education.

\section{CONCLUSION}

From the questionnaire survey, we found that $\sim 56 \%(\mathrm{n}=84)$ of 154 third-year junior high school students in Japan did not understand rocks and minerals as substances supporting industries or daily life. Although we found that the third-year junior high school students did not recognize minerals supporting industries or daily life from the questionnaire survey, 95\% ( $\mathrm{n}=14)$ of the students still could answer the name of minerals, jewels, and rocks. In other words, junior high school students in Japan are likely to simply memorize the names of rocks and minerals. Yet, since junior high school students cannot distinguish between minerals and jewels, many of them may also ambiguously understand the definition of minerals.

In the modern society, with the developmental progress of high-tech equipment, mineral resources have become absolutely indispensable substances. In addition, minerals are one of the most important substances for solving planetary evolution. Thus, crossdisciplinary teaching materials such as for STEM education will definitely be required for the development of geoscience-teaching materials in the 21st century. In this study, knowledge of rocks and minerals by Japanese children was clarified. Therefore, the present study can be one of the most important verified data to determine the direction of earth science education in Japan. Furthermore, it is expected that the development of the 21st century-type educational model would also be important for preparing the STEM teaching materials of earth science not only in Japan but also in other Asian countries.

\section{ACKNOWLEDGEMENT}

I am deeply grateful to my super adviser Prof. Kumano Yoshisuke.

\section{REFERENCE}

Huston, D. L. (2000). Gold in volcanic-hosted massive sulfide deposits: Distribution, genesis, and exploration. In S. G. Hagemann \& P. E. Brown (Eds.), Gold in 2000 (pp. 401-426). GeoScienceWorld. https://doi.org/http://doi.org/10.5382/Rev. 13.12

International Mineralogical Association. (2017). The IMA list of minerals. Retrieved from http://www.imamineralogy.org/Minlist.htm

Kato, Y., Fujinaga, K., Nakamura, K., Takaya, Y., Kitamura, K., Ohta, J., ... Iwamori, H. (2011). Deep-sea mud in the Pacific Ocean as a potential resource for rareearth elements. Nature Geoscience, 4(8), 535-539. https://doi.org/10.1038/ngeo1185

Kumano, Y. (2016). The educational policy development of STEM education innovation in Minnesota and Iowa State and evaluations for the implementation at the Minnesota STEM education center and Iowa Governor's STEM advisory council. JSSE Research Report, 31(8), 93-96. https://doi.org/10.14935/jsser.31.8_93

MEXT. (2017). On the results of the survey on the formation and implementation of curriculum at public high schools. Retrieved from www.mext.go.jp

Ministry of Education Culture Sports Science and Technology. (2017). The courses of study.

Saito, T., Okumura, J., \& Kumano, Y. (2017). The theories and practices which appears in the summer camp as a models of STEM eduation in the informal settting. JSSE, 38, 287-290.

Simon, G., Kesler, S. E., \& Chryssoulis, S. (1999). Geochemistry and textures of gold-bearing arsenian pyrite, Twin Creeks, Nevada; implications for deposition of gold in carlin-type deposits. Economic Geology, 94(3), 405-421. https://doi.org/10.2113/gsecongeo.94.3.40 5

Yakushi, D., \& Enjoji, M. (2004). Chemical composition of Ores from the Takara volcanogenic massive sulfide deposit, Central Japan. Resource Geology, 54(4), 437-446. https://doi.org/10.1111/j.17513928.2004.tb00219.x 